\title{
Traditional Food for Small and Medium Enterprises (SMEs)
}

\author{
Asep Nurhikmat \\ Research Center for Natural Products Technology, \\ Indonesian Institute of Sciences \\ Jl. Jogja - Wonosari km. 31.5, Gading, Playen, \\ Gunungkidul, Yogyakarta \\ asep.nurhikmat@lipi.go.id
}

\author{
Tommy Hendrix \\ Center for Innovation, \\ Indonesian Institute of Sciences \\ Jl. Raya Jakarta Bogor Km. 47 Cibinong 16912 \\ tommy.hendrix@lipi.go.id
}

\begin{abstract}
Studies have been conducted on gudeg canned to increase shelf life. Gudeg is a traditional food based young jackfruit from Yogyakarta Province - Republic of Indonesia with a shelf life of 2 to 3 days. Techniques processing adapted to small and medium industries (SMEs) scale with a capacity of 1000 cans per day and 2 days per week. The study periods were conducted from July 2011 until January 2014. Samples gudeg canned were quarantined at room temperature for 18 months with a sampling interval of 3 months. Tests were conducted on the proximate and organoleptic test. Organoleptic test by panelists, gudeg canned can still be consumed during the storage period of 12 months. Gudeg canned has been registration by the Food and Drug Monitoring Agency - Republic of Indonesia (FDMA RI) with registration number MD 555112005035 .
\end{abstract}

Keywords-Gudeg canned, Traditional food, SMEs

\section{INTRODUCTION}

Food preservation is one form or another is being practiced from ancient times. Since humans are in constant touch with its nature, they have to survive in the conditions available at its nearest vicinity. Food by its nature begins to spoil the moment it is harvested. Early farmers no longer had to consume or harvest immediately, but could preserve some for later use. The tools that need to enhance capacity of the uses in effective food preservation are pattern in management especially in innovation form traditional heritages. Canning can be a safe and economical way to preserve quality of food. Disregarding the value, canning food may save you half the cost of buying commercially canned food. Canning favorite and special products to be enjoyed by family and friends is a fulfilling experience and a source of pride for many people.

When talking about food, tradition is a very large subject that can be described at different levels, within social groups as small as a family or as a function of time scale for example. Traditional foods are also often related to local foods and artisan food referring to specific ingredients, location of the production and know-how. It could be the food made by your grandmother or by the native people of your country (ethnic food). There are some important dates in the history of the food industry [1].

One can consider that the modern food industry was born in the 1930s with the introduction of the household [2]. This mini-revolution was followed during the 1960 s to 1970 s by great modification of structure of the food companies. Many artisan products from SMEs became manufactured products. This characteristic could be an advantage for the preservation of traditional products and for the reactivity to the consumer demand [1]. In the past 15 to 20 years the field has made substantial progress in developing new methods and approaches and in advancing our understanding of consumer responses of foods [3].

For both these approaches, the consumer behavior and the perception of food quality are major parameters to be taken into account. Food quality is a multivariate notion ('it tastes good - it looks traditional, safe, health'). Traditional foods are sometimes used to carry an image of foods tasting good but in the same time could be perceived either good for health (as natural products, no chemical modification, no additives) or bad for health (as related to high fat content, microbial contaminants). These aspects, taste and health, are to be improved in parallel and clarified for the consumers [1]. Growing consumer demands for healthy, nutritious, varied and convenient food has led to continuous improvement of existing techniques, as well as to new development in food processing, designed to produce safe foods while maintaining nutritional and sensory qualities [4][5][6]

Industrialization of food production, European laws on food safety and even the development of innovative products necessitate the characterization of the typical sensory characteristics of these traditional products. For example, it is necessary to specify the characteristics of the traditional products: when Protected Geographical Indication (PGI) or Protected Designation of Origin (PDO) labels are required; when a modification of process is needed to improve food safety; when one have to move from Small-scale production to industrial production; when one have to formulate a new product - low fat products - derived from a traditional one [1] Today, the demand for processed foods goes beyond the fundamental requirements of safety and shelf-stability. More emphasis is being placed on informatively labeled, high quality, and value added foods with convenient end use. Improvements in quality and safety of processed foods have been achieved through regulatory requirements on manufacturers, and national of international legislature the 
recommend and/or enforce performance standards or methods for achieving safety and quality assurance [7].

Food quality can be defined as the sum of the characteristics of a food that determine the satisfaction of the consumer and compliance to legal standards. Thus, food quality is a combination of numerous factors, such as organoleptic properties (for example flavor, texture) nutritional value (for example caloric content, fatty acid composition), shelf life (for example microbial number) and safety conditions (for example presence of pathogens). Some of these (for example microbial numbers) can be relatively easily quantified, while others are very difficult to assess (for example taste). Food quality thus cannot be depend strongly on the priority among food quality, quality indicators are needed and must be weighted, since their relative importance depends on product, trends, producers and market [8]. Thermal processing techniques emphasize the achievement of commercial sterility while minimizing changes in nutritional value and eating quality. However, no matter how minimal the heating source is, thermal processing can promote reactions that could affect overall quality of foods [7]

Quality loss can result from microbial, chemical, enzymatic or physical reactions. Various factors influence quality loss, such as the composition of the product, and the processing and storage conditions [9]. Others factors influencing quality loss are, for example processing and storage conditions (temperature, time, packaging material, gas atmosphere, machinery) [8].

Gudeg, a type of foods from young jackfruit, is one of the most popular in Yogyakarta Province - Republic of Indonesia. Usually, gudeg preserved with rice, chicken meals, egg, crackers cowhide and pea. This type of traditional foods, which generally stored under room conditions ( \pm 25 degrees Celsius) and present a shelf life ranging between 2 and 3 days. Like many other traditional foods whish mostly produced by small family plant, gudeg needs to undergo an inevitable technological evolution to satisfy regulatory safety requirements and the costumer expectations. A more pleasant appearance, shelf life extension, without loss of the traditional taste is main goals of the producers. The addition of already prepared spice mixtures is the key factor.

Thus, the main objectives of this work were to: 1) evaluate production gudeg canned SMEs scale; 2) evaluate shelf life, safety and stability during storage.

\section{MATERIAL AND METHOD}

\section{A. Gudeg production}

Young jackfruits, chicken meals, eggs, crackers cowhide and pea ready to mixture (with composition $47.26 \%$ young jackfruits; $7.79 \%$ chicken meals; $21.54 \%$ eggs; $15.35 \%$ crackers cowhide and $8.06 \%$ pea) processed with canning line became gudeg canned. Techniques processing adapted to SMEs scale with a capacity of 1000 cans per day and 2 days per week. Samples gudeg canned were quarantined at room temperature for 18 months with a sampling interval of 3 months.

\section{B. Stability Analysis}

Analysis conducted on the proximate and organoleptic test. Proximate composition of the sample ware estimated according to [10]. The characteristic covered under the taste panel were flavor, texture and overall acceptability. Multivariate statistical approaches have prompted the development of methods for the analysis of hedonic data, and their interactions [3].

\section{Statistic Analysis}

Statistical treatment of data was performed using Linear Regression from Excel® for production capacity gudeg canned SMEs scale and microbial test at storage time. Correlation analysis from Statistical Products and Service Solutions (SPSS) for Windows was performed statistical treatment for correlation among nutrient value gudeg canned at storage time. Scatter plot from Excel® was performed for organoleptic test.

\section{RESULTS}

Technological innovations in food preservation were dependent on advances in the sciences, especially chemistry and microbiology. How these sciences and technologies are applied within each society depends on the economic, biological, cultural, and political contexts for each society. Advances in agriculture and food science and technology have

led to reduction in nutrient deficiency-related diseases; a generally safe food supply with consistent high quality available independent of seasons; food choices that do not require preparation time; a wide range of delicious foods; reduced food waste; lower household food costs than ever before; convenience foods requiring much less preparation time than before, a benefit for working families; and efficient global food distribution that can be exploited in times of natural and man-made disasters. Management preservation on canning food need to be accelerated in enhancing possibility in development of business oriented. Commercialization side, can develop economic value and brand image of product that came from rural area.

To preserve Small Medium Enterprises (SMEs) on producing need line producing concept that consist of stage production (Fig. 1) especially standard operational procedure linked with capacity production 500 can of gudeg [11]. 


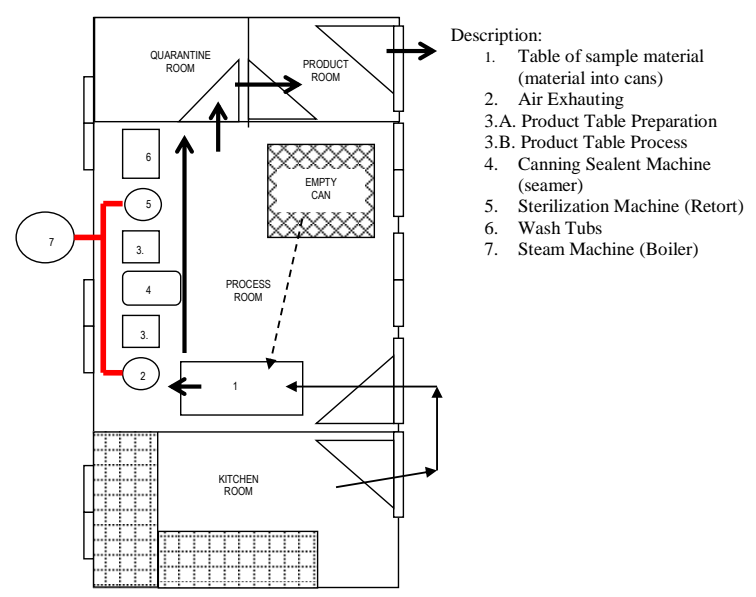

Fig. 1. Canning Room Production for SMEs

The design is done with the procedure: specify the number of departments and department names, define Department considered constraint, embodying the initial layout with size and determine the flow between departments [12]. Based on the results simulations, chosen facility layout based on minimization of material handling, consideration of the development of layout, the limitations of space and the way a good food production.

SMEs capacity in production gudeg canned increase $20 \%$ from production average per day that is $1,115.96$ cans with deviation standard 132.69 cans (Fig. 2). Product reject duration gudeg canned production $<0.5 \%$ or 2 cans from production average per day.

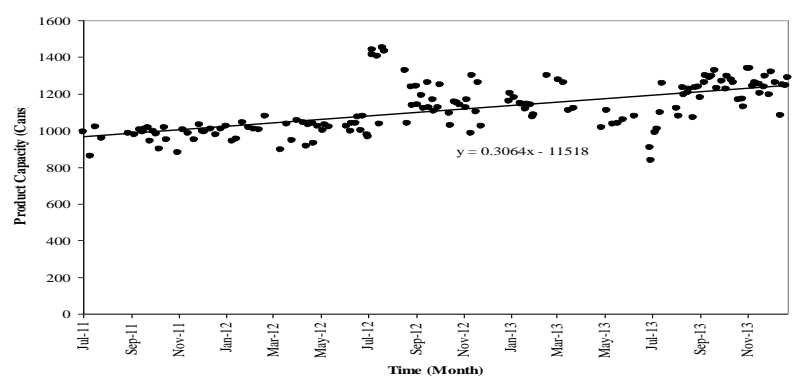

Fig. 2. Productions capacity on gudeg canned SMEs scale

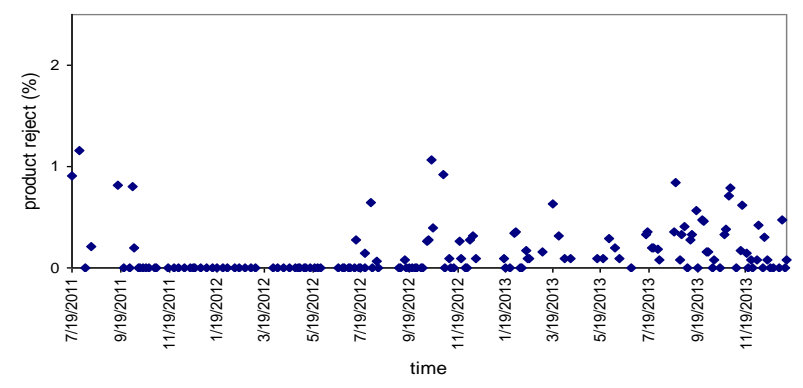

Fig. 3. Product reject on gudeg canned SMEs scale

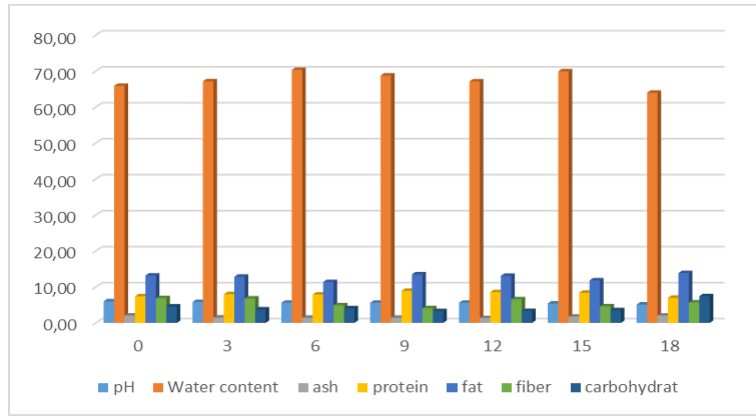

Fig. 4. Proximate analysis gudeg canned during storage.

Fig. 4 shows nutrient value from gudeg canned during storage. The water content of gudeg canned was generally very high (66.675\% to $68.804 \%)$. Protein content was very high (7.304 \% to $8.142 \%$ ) derived from eggs, crackers cowhide and pea. Average nutrient value from gudeg canned that is 67.739 $\%$ water; $1.654 \%$ ash; $7.723 \%$ proteins; $13.094 \%$ fat; 5.577 $\%$ fiber and $3.924 \%$ carbohydrate and 167.659 cal per $100 \mathrm{~g}$ energy.

Organoleptic characteristics were determined on a 5 points hedonic scale using a non- trained panel of 30 members. The characteristics covered under the taste panel were flavor, texture and overall acceptability. Sensory evaluation of gudeg canned was carried out at regular intervals of 3 months. Organoleptics test to gudeg canned presented in Fig. 2.

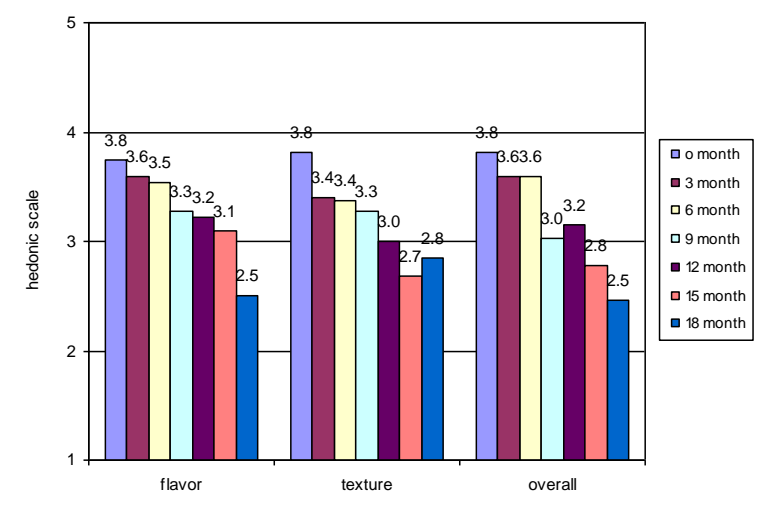

Fig. 5. Organoleptic test gudeg canned at 18 Months storage.

Response of members still like gudeg canned until 15 Months storage with an average value of 3 to 3.2 (likely). 


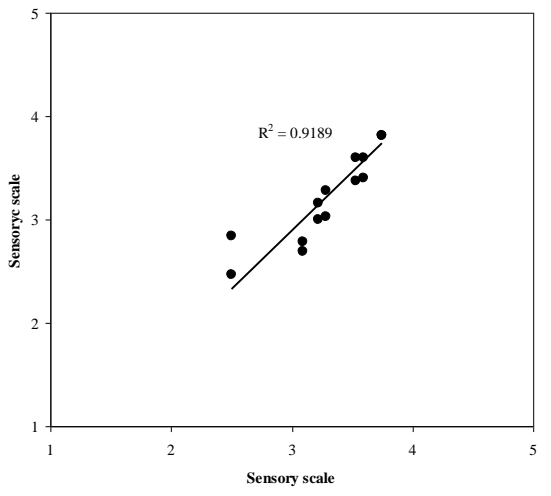

Fig. 6. Regression analysis of the sensory quality gudeg canned.

Regression analysis of the sensory quality produce $\mathrm{R}$ square value of 0.919 (Fig. 3), this means that storage affects the sensory quality (flavor, texture and overall) gudeg canned. Heating above the pasteurization temperature will alter the physical and chemical gudeg canned. During thermal processing, the protein will undergo coagulation and precipitation. Solving the network during heating will modify the texture of gudeg canned. After sterilization, texture turn into ripe and ready to eat.

\section{DISCUSSION}

Canning is a method of sterilizing food by heat in hermetically sealed (airtight) containers, which allows readyto-eat foods that are neither frozen nor dehydrated to remain safe and wholesome during months or even years of storage at room temperature without the use of additives or preservatives. In addition to playing an important role in the feeding of humankind throughout the world, this technology is used to produce a wide variety of sterile hospital solutions and pharmaceuticals for the health care industry. Within the food industry and food science community, this technology is referred to as thermal processing [13].

As traditional food, flavors of gudeg depended on the raw material, the number of constituent components and preservation. Raw materials of gudeg come from nature native Indonesia with added spices and then cooked to produce a special taste from gudeg. Since the start of the selection of raw materials, preparation component and preservation and vary from one producer to other producer cause no standards to make gudeg. This is the challenge to create gudeg canned which all stages have to do with regular and standardized. Gudeg with canning process depends on the standard of production and wishes manufacture to developing alternative packaging.

Gudeg with canning process involves many factors which of one was the availability of raw materials. To produce gudeg canned of approximately 1,000 cans, then producer takes 2 to 3 days from raw materials supplied, especially young jackfruit and preservation process. To production gudeg required 24 hours cooking time starting from the raw materials became gudeg. At the time of filling, because the number of components made up 5 to 6 kinds where one component with each other very different, then processes used human labor. Cause that needed evaluation every time to standardized processing.

In canning process, that could be overcome by the effects of sterilization. Sterilization must consider the amount of heat given and time. The heat should be enough destroy microbes on one component but not enough to lower the nutritional and sensory quality of the other components. [14] Reported a higher temperature-shorter time process will favor retention of nutrients and quality factor in foods including color, texture, flavor and nutrient, constituents that are destroyed through conventional chemical reaction. Conventional thermal processing relies on the effect of temperature on food constituents followed by appropriate packaging and storage condition.

[15] Reported in view of the considerable advancement in technological processes and development of several new products to provide variety in the diet, based on the consumer demand, it is necessary to update the existing database with respect to both macro and micro nutrient. One key desired effect of food processing is to increase food safety, microbiological as well as chemical. Other desired effects are increased storage times, improved texture and flavor, and the reduction of anti-nutritional effects [16]. [17] Reported that the definition of food characteristics by sensory analysis is important to establish the specificity or typicality of the products. Then profiling tests appeared allowing to characterize the differences perceived between samples. Traditional evaluation of sensory characteristics of food product consists of establishing sensory profiles. The complexity of the tasks asked to the panel increased and longer training periods together with more complex statistical analysis were required. In fact, the use of results obtained by sensory analysis could be limited by the variability of perception among individuals. This variability could be linked with differences in anatomy, in physiology, but also in the culture of the panelists [18] concerning the modulation of olfactory capacity with age, gender, habits or disease. Responses of specific age groups, such as children and elderly, became increasingly interesting to researchers and relevant industries [3].

\section{CONCLUSION}

In general, foods canned can be accepted by the market, but there are some things that need to be considered include the selection of appropriate technology canning process so that foods canned is not nutrient content decreased significantly. This research needs to be done so that the nutritional composition of food in cans has not changed much with fresh ingredients. Based on proximate analysis and stability test have been carried out and in accordance with SNI, gudeg canned got registration number MD 555112005035 from FDMA RI and can be consumed up to 12 months of storage. 


\section{ACKNOWLEDGMENT}

Thank you to Agus Susanto as Leader in Canning Team and Canning Teams Research Unit for Natural Products Technology - Indonesian Institute of Sciences (BPTBA LIPI).

\section{REFERENCES}

[1] Cayot, N. 2007. Sensory Quality of Traditional Food. Food Chemistry 101: $154-162$

[2] Anonymous. 2005. History of Fozen Foods: Long and Varied. American Frozen Food Institute.

[3] Tuorila, H and E. Monteleone. 2009. Sensory Food Science in the Changing Society: Opportunities, Needs, and Challenges. Trends in Food Science and Technology 20: 54-62.

[4] Zink, D.L. 1997. The Impact of Consumer Demands and Trends on Food Processing. Emerg. Infect. Dis. 3(4): 467-469.

[5] Lado, B.H. and A.E. Yousef. 2002. Alternative Food-preservation Technologies; Efficacy and Mechanism. Microb. Infect. 4. pp. 433-440.

[6] Tritscher, A.M. 2004. Human Health Risk Assessment of Processingrelated Compounds in Food. Toxicology Letters 149: 177-186.

[7] Awuah, G.B., H.S. Ramaswamy and A. Economides. 2007. Thermal Processing and Quality: Principles and Overview. Chemical Engineering and Processing 46: 584-602.

[8] Zwietering, M.H., F.M. Rombouts and K. Van't Riet. 1993. Some Aspect of Modelling Microbial Quality of Food. Food Control 1993 4(2): 89-96
[9] Fennema, O.R. (Ed). 1985. Food Chemistry. Marcel Dekker. New York.

[10] AOAC. 1984. Official methods of analysis. In S. Williams (Ed.) 14th ed. Association of Official Analytical Chemists. Arlington. VA.

[11] Hendrix, T. and Nurhikmat, A. 2014. Preliminary Study Of Canning Fish Scale Of SMEs In The Province Riau. National Seminar PATPI, pp. 93-101.

[12] Sun, S.G. and Wahyudi, D. 2000. Analysis of The Layout Of The Plant To Minimize Material Handling On Factory Suitcase. Journal of Mechanical Engineering University of Petra, vol. 2 (1): 41-49

[13] Teixeira, A.A., Dixon, J.R. Zahradnik, J.W. and Zinsmeister, G.E. 1969. Computer Optimization of Nutrient Retention in the Thermal Processing of Conduction Heated Foods. Food Technology, 23, pp. 845-850.

[14] Lund, D. 2003. Predicting the Impact of Food Processing on Food Constituents. Journal of Food Engineering 56: 113-117.

[15] Prasad, N.N., M. Siddalingaswamy, P.M. Parameswaiah, K Radhakrishna, R.V. Rao, K.R. Viswanathan and K. Santhanam. 2000. Proximate and Mineral Composition of some Processed Traditional and Popular Indian Dishes. Food Chemistry 68: 87-94.

[16] Friedman, M. 1992. Dietary Impact of Food Processing. Annu. Rev. Nutri. 12: 119-137.

[17] Chollet, S. and D. Valentin. 2001. Le degree d'expertise a-t-il une influence sur la perception olfactive? Quelques elements de reponse dans le domaine du vin. L'annee psychologique. 100: 11-36.

[18] Tanaka, M., Y. Nagashima and T. Taguchi. 1985. Quality Comparison of Mackerel Canned with Equal Lethality. Buletin of The Japan Society of Science and Fisheries 5(10): 1737-1742. 